\title{
Synthesis, structure and photocatalytic properties of $\beta-\mathrm{ZrMo}_{2} \mathrm{O}_{8}$
}

\author{
PRANGYA PARIMITA SAHOO, S SUMITHRA, GIRIDHAR MADRAS and \\ T N GURU ROW* \\ Solid State and Structural Chemistry Unit, Indian Institute of Science, Bangalore 560 012, India
}

\begin{abstract}
Monoclinic $\mathrm{ZrMo}_{2} \mathrm{O}_{8}$ was synthesized via solid state method and single crystals of the title compound have been grown by the hydrothermal method. The crystals belong to monoclinic crystal system with space group $C 2 / c$ (No. 15) with $a=11 \cdot 4243(19) \AA, b=7.9297(6) \AA, c=7 \cdot 4610(14) \AA$ and $\beta=122 \cdot 15(2)^{\circ}, Z=4$. The bandgap of the compound was $2.57 \mathrm{eV}$. Unlike the other polymorphs of $\mathrm{ZrMo}_{2} \mathrm{O}_{8}$, the monoclinic form has unique crystallographic features with $\mathrm{ZrO}_{8}$ and $\mathrm{Mo}_{2} \mathrm{O}_{8}$ polyhedra. The photocatalytic activity of this compound has been investigated for the first time for the degradation of various dyes under UV irradiation and has been compared with the photoactivity of the trigonal form of $\mathrm{ZrMo}_{2} \mathrm{O}_{8}$. It has been observed that this compound exhibits specificity towards the degradation of cationic dyes.
\end{abstract}

Keywords. Zirconium molybdate; crystal growth; X-ray diffraction; crystal structure; photocatalysis; dye degradation.

\section{Introduction}

$\mathrm{ZrMo}_{2} \mathrm{O}_{8}$ is one of the well studied compounds in recent literature particularly with reference to its polymorphic modifications, phase transitions and negative thermal expansion. The structural flexibility associated with this molecule allows itself to be adopted to various polymorphic forms. Amongst them, at ambient pressure the most stable polymorphs are the $\alpha$ and $\beta$ forms. The single crystal structure of $\alpha-\mathrm{ZrMo}_{2} \mathrm{O}_{8}$ was solved in trigonal crystal system with space group $P \overline{3} 1 c$ (No. 163) with $a=10 \cdot 1391(6) \AA, c=11.7084(8) \AA$ and $Z=6$ (Auray et $a l$ 1986). They have also solved the structure of the $\beta$ $\mathrm{ZrMo}_{2} \mathrm{O}_{8}$ in the monoclinic crystal system with space group $C 2 / c$ (No. 15) with $a=11.4309$ (3) $\AA, b=7.9376(2) \AA$, $c=7.4619$ (2) $\AA$ and $\beta=122.323$ (2) ${ }^{\circ}, Z=4$ (Auray et al $1989)$. In the same year, Klevtsova et al (1989) reported the single crystal structure of this polymorph and published the coordinates of all the constituent atoms. It is also to be noted that the negative thermal expansion materials, viz. the cubic and the orthorhombic LT- $\mathrm{ZrMo}_{2} \mathrm{O}_{8}$ have also been prepared via careful dehydration of the precursor, $\mathrm{ZrMo}_{2} \mathrm{O}_{7}(\mathrm{OH})_{2} \cdot 2 \mathrm{H}_{2} \mathrm{O}$ at $365-390^{\circ} \mathrm{C}$ and $300^{\circ} \mathrm{C}$, respectively (Lind et al 1998; Allen et al 2003). The linear thermal expansion coefficients are $-5.0 \times 10^{-6} \mathrm{~K}^{-1}$ and $-1.2 \times 10^{-6} \mathrm{~K}^{-1}$ for the cubic and the LT polymorphs, respectively.

Under the influence of temperature and pressure the polymorphs of $\mathrm{ZrMo}_{2} \mathrm{O}_{8}$ undergo phase transitions. The monoclinic to trigonal transformation occurs at around $690^{\circ} \mathrm{C}$ (Auray et al 1989). The cubic form undergoes a

*Author for correspondence (ssctng@sscu.iisc.ernet.in) phase transformation to the trigonal form above $390^{\circ} \mathrm{C}$ and this behaviour has been studied via time resolved $\mathrm{X}$-ray diffraction (Lind et al 2002). Further, the trigonal form $\left(\alpha-\mathrm{ZrMo}_{2} \mathrm{O}_{8}\right)$ undergoes a second order phase transition at around $215^{\circ} \mathrm{C}$ to $\alpha^{\prime}-\mathrm{ZrMo}_{2} \mathrm{O}_{8}$ with space group $P \overline{3} m 1$ (No. 164) with $a=5.8460(6) \AA, c=$ 5.9941(8) A (Allen et al 2004). Two completely reversible phase transitions occur for $\alpha-\mathrm{ZrMo}_{2} \mathrm{O}_{8}$ at 1.06$1 \cdot 11 \mathrm{GPa}$ and $2 \cdot 0-2 \cdot 5 \mathrm{GPa}$, respectively. The phases have been named as $\delta$ and $\varepsilon$ phases and they belong to the monoclinic and triclinic crystal systems, respectively (Carlson and Andersen 2000; Andersen and Carlson 2001). High pressure studies using Raman, infrared, optical absorption spectra and resistance measurements on trigonal polymorph have been performed recently and show the consistency of the spectroscopic techniques with the diffraction results (Muthu et al 2002; Karandikar et al 2006). High pressure X-ray diffraction experiments on cubic $\mathrm{ZrMo}_{2} \mathrm{O}_{8}$ have revealed a first order phase transition above $0.7 \mathrm{GPa}$ when compressed hydrostatically and under non-hydrostatic condition amorphization commences above $0.3 \mathrm{GPa}$ (Lind et al 2001). The simultaneous application of both temperature and pressure on the cubic form generates the stable $\alpha$-trigonal and the $\beta$-monoclinic forms (Grzechnik and Crichton 2002).

Apart from negative thermal expansion, various other properties have been analyzed. For example, $\mathrm{ZrMo}_{2} \mathrm{O}_{8}$ gel finds important applications as inorganic ion exchangers (Clearfield and Blessing 1972; Monroy-Guzmán et al 2003). The trigonal $\mathrm{ZrMo}_{2} \mathrm{O}_{8}$ consists of $\mathrm{ZrO}_{6}$ octahedra and $\mathrm{MoO}_{4}$ tetrahedra wherein the fourth oxygen atom $\mathrm{O}(4)$ points towards the interlayer region. This feature gives rise to various properties like resistance, luminescence and more recently catalysis (Blasse and Dirksen 
1987; Karandikar et al 2006; Sahoo et al 2009). In order to develop novel energy storage devices, lithium and sodium insertion to monoclinic and trigonal form has been attempted. The monoclinic structure could accept up to two $\mathrm{Li}$ atoms per formula unit whereas amorphization occurred for the trigonal polymorph (Sudorgin et al 2009).

Semiconductor photocatalysis is an area of interest in environmental remediation ever since the discovery of the most widely used photocatalyst, $\mathrm{TiO}_{2}$ (Fujishima and Honda 1972). In recent years focus is on non- $\mathrm{TiO}_{2}$ based catalysts which have resulted in evaluation of photocatalytic properties of $\mathrm{PbBi}_{2} \mathrm{Nb}_{2} \mathrm{O}_{9}, \mathrm{BiVO}_{4}$ and $\mathrm{ZnWO}_{4}$ (Kudo et al 1999; Kim et al 2004; Fu et al 2006).

In our recent work, we have discussed the photocatalytic activity of the trigonal form of $\mathrm{ZrMo}_{2} \mathrm{O}_{8}$ synthesized via two different routes, viz. the routine solid state technique and the combustion synthesis method (Sahoo et al 2009). To the best of our knowledge, there has been no report of the catalytic activity of various polymorphs of $\mathrm{ZrMo}_{2} \mathrm{O}_{8}$. The previous reports on the single crystal structure determination of the monoclinic $\mathrm{ZrMo}_{2} \mathrm{O}_{8}$ did not treat the atoms anisotropically. Further, the current datasets have been obtained on a four circle diffractometer with a very high precision and the determination of the structure is rigorous. In the current paper, we discuss the synthesis, single crystal growth, crystal structure and photocatalytic activity of the thermodynamically stable monoclinic polymorph and compare its activity with the trigonal form.

\section{Experimental}

\subsection{Materials}

$\mathrm{ZrO}_{2}$ was synthesized by heating $\mathrm{Zr}\left(\mathrm{NO}_{3}\right)_{4} \cdot 5 \mathrm{H}_{2} \mathrm{O}(\mathrm{BDH}$ England, $99 \%$ ) for $4 \mathrm{~h}$ at $550^{\circ} \mathrm{C} . \mathrm{MoO}_{3}$, methylene blue $(\mathrm{MB})$, orange $\mathrm{G}(\mathrm{OG})$, rhodamine $\mathrm{B}(\mathrm{RB})$, remazol brilliant blue R (RBBR), malachite green (MG) and congo red (CR) (all from S.D. Fine-Chem Ltd., India) were used. Water was double distilled and filtered through a Millipore membrane filter prior to use.

\subsection{Synthesis and crystal growth}

For the preparation of monoclinic $\beta-\mathrm{ZrMo}_{2} \mathrm{O}_{8}, \mathrm{ZrO}_{2}$ and $\mathrm{MoO}_{3}$ were taken in the ratio of $1: 2$. The heat treatment was conducted according to the procedure mentioned in the literature (Auray et al 1989). The composition was ground well and the resulting mixture was fired at $600^{\circ} \mathrm{C}$ for $48 \mathrm{~h}$ with a heating rate of $10^{\circ} \mathrm{C} / \mathrm{min}$ with an intermediate grinding after $24 \mathrm{~h}$.

The crystals were grown by hydrothermal method. The monoclinic $\mathrm{ZrMo}_{2} \mathrm{O}_{8}$, synthesized by solid state method was taken as the starting material for obtaining the single crystals. Approximately $0.5 \mathrm{~g}$ of the monoclinic sample was transferred to a Teflon lined autoclave. Then $15 \mathrm{~mL}$ of distilled water was added, stirred for $15 \mathrm{~min}$ and then kept in an oven at $180^{\circ} \mathrm{C}$ for 5 days. The resultant product was filtered out and dried in air. Very small colourless crystals appeared on the surface of the product. Crystals suitable for X-ray diffraction were carefully selected under the microscope.

\subsection{Characterization}

2.3a Single crystal X-ray diffraction: A colourless plate like single crystal was selected on the basis of size and sharpness of diffraction spots. Data collection was carried out on an Oxford Xcalibur MOVA diffractometer using a graphite monochromatized $\operatorname{MoK} \alpha$ wavelength $\left(\lambda_{\mathrm{MoK} \alpha}=0.71073 \AA\right)$ radiation at $293(2) \mathrm{K}$. The data were reduced using special programs available with the diffractometer. The structure was solved by direct methods using SHELXS97 and refined using SHELXL97 (Sheldrick 1997). Crystallographic data and the details of the single-crystal data collection are given in table 1. Atomic coordinates and isotropic displacement parameters are presented in table 2. Anisotropic displacement parameters (ADPs) and selected inter atomic distances are given in tables 3 and 4 . The bond valence sums were calculated (Brown and Shannon 1973; Brown and Altermatt 1985) and are given in table 4.

Table 1. Crystallographic data collection and structure refinement of monoclinic $\mathrm{ZrMo}_{2} \mathrm{O}_{8}$.

\begin{tabular}{|c|c|}
\hline Empirical formula & $\mathrm{ZrMo}_{2} \mathrm{O}_{8}$ \\
\hline Formula weight & $411 \cdot 10$ \\
\hline Crystal habit, colour & Plate, colourless \\
\hline Crystal size (mm) & $0.017 \times 0.010 \times 0.007$ \\
\hline Temperature $(\mathrm{K})$ & $293(2)$ \\
\hline Radiation & Molybdenum \\
\hline Wavelength $(\AA)$ & 0.71073 \\
\hline Crystal system & Monoclinic \\
\hline Space group & $C 2 / c$ \\
\hline$a(\AA)$ & $11.4243(19)$ \\
\hline$b(\AA)$ & $7 \cdot 9297(6)$ \\
\hline$c(\AA)$ & $7 \cdot 4610(14)$ \\
\hline$\beta\left(^{\circ}\right)$ & $122 \cdot 15(2)$ \\
\hline Volume $\left(\AA^{3}\right)$ & $572 \cdot 3(2)$ \\
\hline Z & 4 \\
\hline Density $\left(\mathrm{g} \mathrm{cm}^{-3}\right)$ & $4 \cdot 771$ \\
\hline$F(000)$ & 752 \\
\hline Scan mode & $\omega$ scans \\
\hline$\theta_{\max }\left({ }^{\circ}\right)$ & $32 \cdot 7$ \\
\hline$h_{\min , \max }, k_{\min , \max }, l_{\min , \max }$ & $(-17,17),(-11,11),(-11,11)$ \\
\hline No. of reflns measured & 992 \\
\hline No. of unique reflns & 902 \\
\hline$\mu\left(\mathrm{mm}^{-1}\right)$ & 4.576 \\
\hline No. of parameters & 52 \\
\hline Refinement & $F^{2}$ \\
\hline$R \_$all, $R \_$obs & $0 \cdot 0219,0 \cdot 0187$ \\
\hline$w R_{2 \_}$all, $w R_{2 \_}$obs & $0 \cdot 0425,0 \cdot 0419$ \\
\hline GoF & 1.073 \\
\hline $\operatorname{Max}, \min \Delta \rho\left(\mathrm{e} / \AA^{3}\right)$ & $0.876,-0.845$ \\
\hline
\end{tabular}


Table 2. Atomic coordinates $(\AA)$ and isotropic displacement parameters $\left(\AA^{2}\right)$ for monoclinic $\mathrm{ZrMo}_{2} \mathrm{O}_{8}$.

\begin{tabular}{llclcc}
\hline $\begin{array}{l}\text { Atomic and } \\
\text { Wyckoff position }\end{array}$ & \multicolumn{1}{c}{$x$} & \multicolumn{1}{c}{$y$} & \multicolumn{1}{c}{$z$} & $U_{\text {eq }}\left(\AA^{2}\right)$ & Occupancy \\
\hline $\mathrm{Zr}(4 e)$ & 0 & $-0 \cdot 01766(4)$ & $0 \cdot 25$ & $0 \cdot 0045(1)$ & 1 \\
$\mathrm{Mo}(8 f)$ & $0 \cdot 21495(2)$ & $0 \cdot 27919(3)$ & $0 \cdot 25770(3)$ & $0 \cdot 0071(1)$ & 1 \\
$\mathrm{O}(1)(8 f)$ & $0 \cdot 0926(2)$ & $0 \cdot 1147(2)$ & $0 \cdot 0769(3)$ & $0 \cdot 0085(5)$ & 1 \\
$\mathrm{O}(2)(8 f)$ & $0 \cdot 3464(2)$ & $0 \cdot 3368(2)$ & $0 \cdot 5617(3)$ & $0 \cdot 0109(5)$ & 1 \\
$\mathrm{O}(3)(8 f)$ & $0 \cdot 3511(2)$ & $0 \cdot 2984(3)$ & $0 \cdot 2119(3)$ & $0 \cdot 0110(5)$ & 1 \\
$\mathrm{O}(4)(8 f)$ & $0 \cdot 1290(2)$ & $0 \cdot 4615(3)$ & $0 \cdot 1678(4)$ & $0 \cdot 0201(6)$ & 1 \\
\hline
\end{tabular}

Table 3. Anisotropic displacement parameters $\left(\AA^{2}\right)$ of monoclinic $\mathrm{ZrMo}_{2} \mathrm{O}_{8}$.

\begin{tabular}{|c|c|c|c|c|c|c|}
\hline Atom & $U_{11}$ & $U_{22}$ & $U_{33}$ & $U_{23}$ & $U_{13}$ & $U_{12}$ \\
\hline $\mathrm{Zr}$ & $0 \cdot 0041(2)$ & $0 \cdot 0050(1)$ & $0 \cdot 0040(2)$ & 0 & $0.0018(1)$ & 0 \\
\hline Mo & $0 \cdot 0073(1)$ & $0 \cdot 0083(1)$ & $0 \cdot 0052(1)$ & $-0 \cdot 0012(1)$ & $0 \cdot 0030(1)$ & $-0 \cdot 0029(1)$ \\
\hline $\mathrm{O}(1)$ & $0 \cdot 0077(8)$ & $0 \cdot 0100(8)$ & $0 \cdot 0077(9)$ & $-0.0017(7)$ & $0.0041(7)$ & $-0.0020(6)$ \\
\hline $\mathrm{O}(2)$ & $0 \cdot 0114(8)$ & $0 \cdot 0155(9)$ & $0 \cdot 0061(9)$ & $-0.0034(7)$ & $0 \cdot 0048(7)$ & $-0.0072(7)$ \\
\hline $\mathrm{O}(3)$ & $0 \cdot 0106(9)$ & $0 \cdot 0152(9)$ & $0.0078(9)$ & $-0.0026(7)$ & $0 \cdot 0053(8)$ & $-0 \cdot 0047(7)$ \\
\hline $\mathrm{O}(4)$ & $0 \cdot 0173(10)$ & $0 \cdot 0139(10)$ & $0 \cdot 0199(11)$ & $-0 \cdot 0027(8)$ & $0.0038(9)$ & $0.0016(8)$ \\
\hline
\end{tabular}

Table 4. Selected bond lengths of monoclinic $\mathrm{ZrMo}_{2} \mathrm{O}_{8}$.

\begin{tabular}{llcc}
\hline Bond length type & Distance $(\AA)$ & Bond length type & Distance $(\AA)$ \\
\hline Mo-O(1) & $1 \cdot 862(2)$ & $\mathrm{Zr}-\mathrm{O}(1) \times 2$ & $2 \cdot 312(2)$ \\
$\mathrm{Mo}-\mathrm{O}(2)$ & $1.995(2)$ & $\mathrm{Zr}-\mathrm{O}(1)^{\prime} \times 2$ & $2 \cdot 217(2)$ \\
$\mathrm{Mo}-\mathrm{O}(2)^{\prime}$ & $2 \cdot 039(2)$ & $\mathrm{Zr}-\mathrm{O}(2) \times 2$ & $2 \cdot 118(2)$ \\
$\mathrm{Mo}-\mathrm{O}(3)$ & $1.768(3)$ & $\mathrm{Zr}-\mathrm{O}(3) \times 2$ & $2 \cdot 142(3)$ \\
$\mathrm{Mo}-\mathrm{O}(4)$ & $1.674(2)$ & & \\
$\mathrm{BVS}$ & 5.962 & $\mathrm{BVS}$ & 4.202 \\
\hline
\end{tabular}

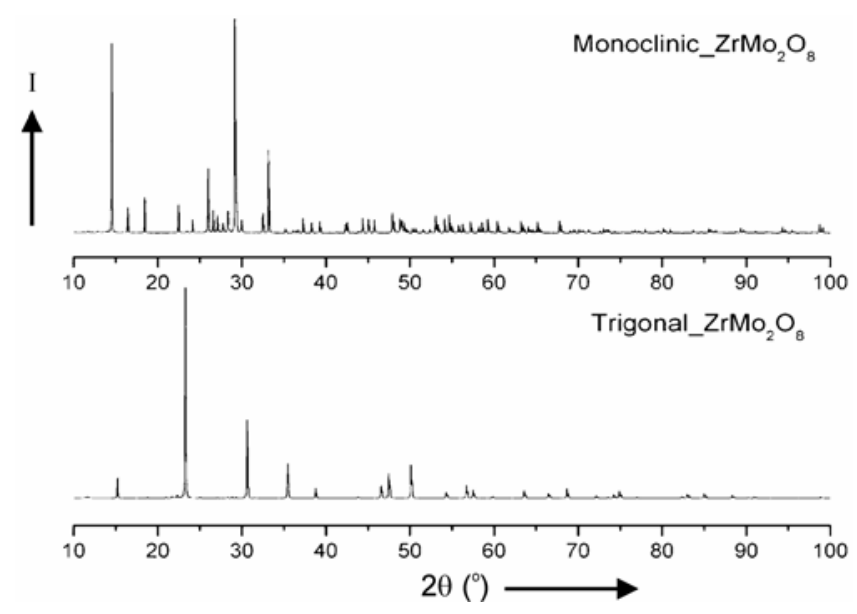

Figure 1. Powder $\mathrm{X}$-ray diffraction patterns of monoclinic and trigonal $\mathrm{ZrMo}_{2} \mathrm{O}_{8}$.

2.3b Powder X-ray diffraction and UV-vis spectra: Powder X-ray diffraction data were collected using the Philips X-pert Pro diffractometer with $\mathrm{CuK} \alpha$ radiation over the angular range $10^{\circ} \leq 2 \theta \leq 100^{\circ}$, with a step width of $0.02^{\circ}$. Powder diffraction data show the formation of a single phase compound for monoclinic $\mathrm{ZrMo}_{2} \mathrm{O}_{8}$. For comparison, the powder diffraction patterns of the monoclinic and the trigonal forms are given in figure 1.

Le Bail profile analysis in the JANA2000 suite was used to refine the X-ray diffraction data (Dušek et al 2001). The background was estimated by Legendre polynomial, and the peak shapes were described by a pseudoVoigt function varying five profile coefficients. The experimental, calculated and the difference profiles for monoclinic $\mathrm{ZrMo}_{2} \mathrm{O}_{8}$ are presented in figure 2 .

The UV-vis diffuse reflectance spectra were recorded on a Perkin Elmer Lambda 35 UV-vis Spectrophotometer. The bandgap calculated for the monoclinic form is $2.57 \mathrm{eV}$ as compared to $2.74 \mathrm{eV}$ for the trigonal polymorph (Sahoo et al 2009). Figure 3 shows the solid state UV diffuse reflectance spectra of the monoclinic and the trigonal polymorphs.

\subsection{Photocatalytic experiments}

2.4a Photochemical reactor: The photochemical reactor used in this study has two parts. The inner part is a jacketed quartz tube whereas the outer part is a pyrex glass reactor. A high pressure mercury vapour lamp (HPML) of $125 \mathrm{~W}$ (Philips, India) was placed after the 


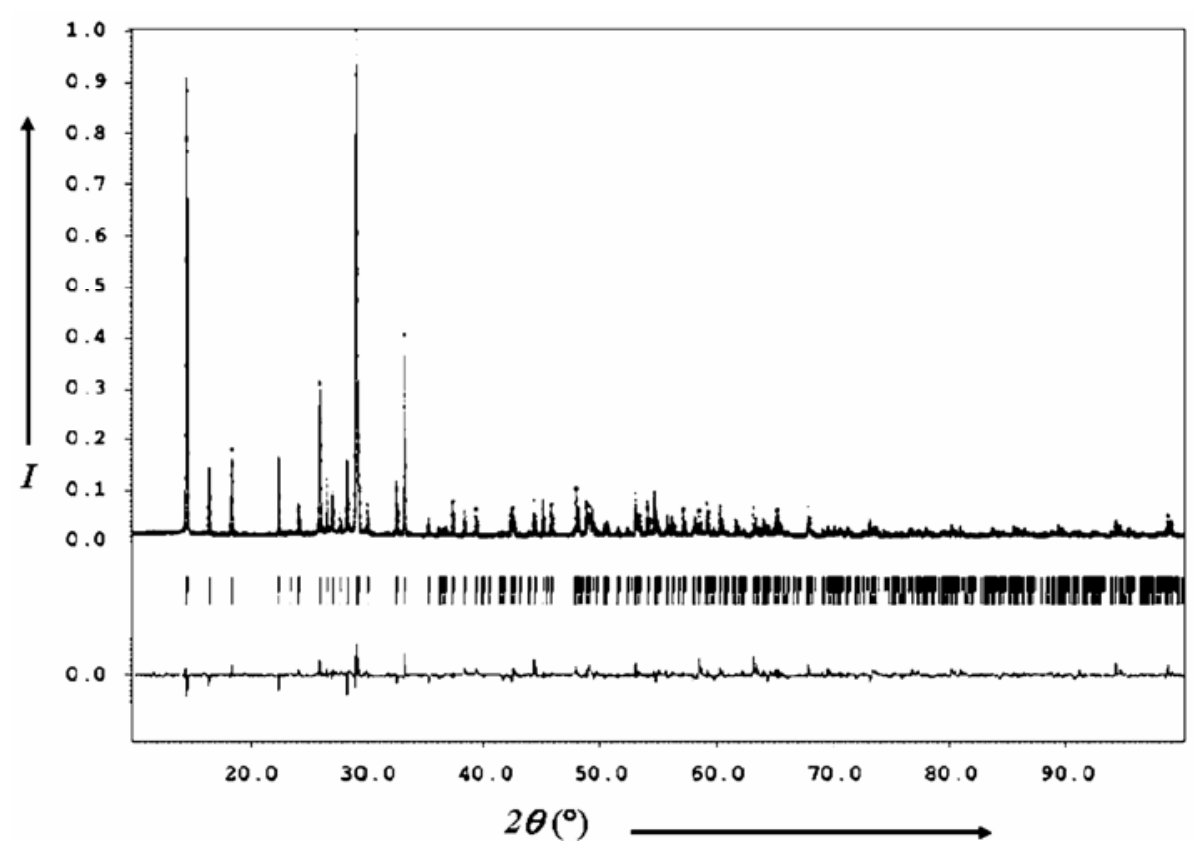

Figure 2. Experimental (dashed) and calculated (solid line) X-ray diffraction profiles of monoclinic $\mathrm{ZrMo}_{2} \mathrm{O}_{8}$. The difference profile is located at the bottom.

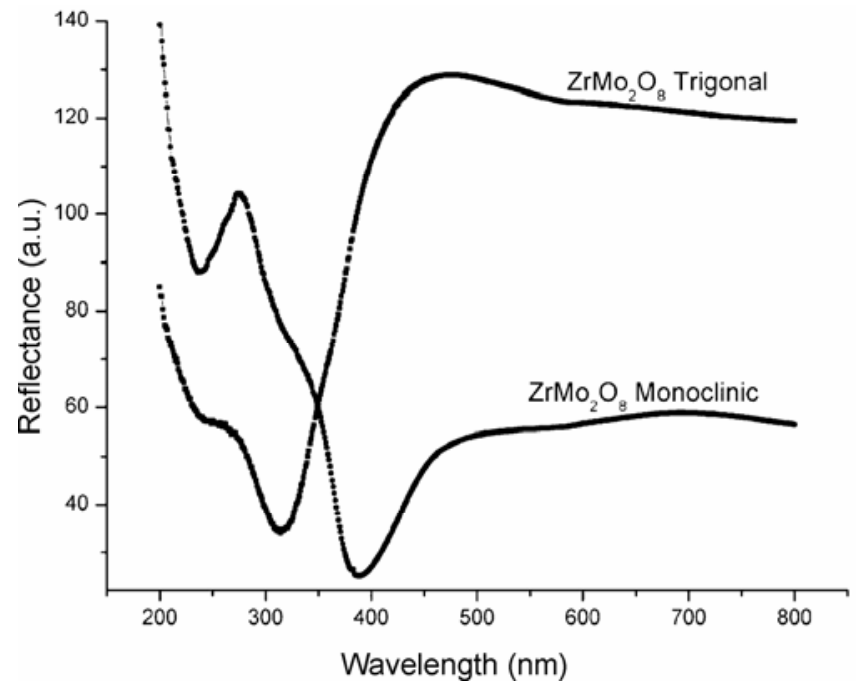

Figure 3. Diffuse reflectance spectra of monoclinic and trigonal $\mathrm{ZrMo}_{2} \mathrm{O}_{8}$.

removal of the outer shell. Water circulates through the annulus of the quartz tube, maintaining the temperature of the suspension at ambient temperature. $100 \mathrm{ml}$ of the solution is taken into the outer reactor and continuously stirred to ensure that the suspension of the catalyst is uniform. The lamp radiated primarily at $365 \mathrm{~nm}$. Extensive details of the experimental set up are provided elsewhere (Sivalingam et al 2003).

2.4b Degradation experiments: The initial concentrations in the dye solutions varied between 15 and $100 \mathrm{ppm}$

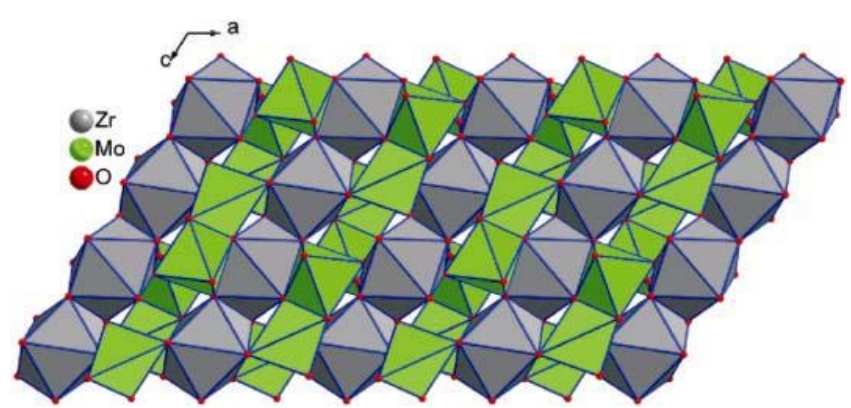

Figure 4. Structure of monoclinic $\mathrm{ZrMo}_{2} \mathrm{O}_{8}$ along $b$ axis.

depending on the molar absorptivity $(\varepsilon)$ of each dye. The catalyst loading was $0 \cdot 1 \mathrm{~g}$ and the volume of the dye solution taken was $100 \mathrm{~mL}$ in all the experiments. The solution was stirred for $1 \mathrm{~h}$ in dark to account for any adsorption. $4 \mathrm{~mL}$ of the solution was drawn 6 times over a span of $1 \mathrm{~h}$ for UV experiments. The samples were filtered through Millipore membrane filters and centrifuged to remove the catalyst particles prior to UV analysis.

2.4c Sample analysis: All samples were analysed with a UV-visible spectrophotometer (Lambda 35, PerkinElmer) to quantify the degradation reactions. The calibration for MB, OG, RB, RBBR, CR and MG were based on Beer-Lambert law at their maximum absorption wavelengths, $\lambda_{\max }$ of $664,489,554,591,497$ and $615 \mathrm{~nm}$, respectively. The analysis of the samples using UV-vis spectrophotometer showed a continuous decrease in the UV-vis absorption at $\lambda_{\max }$ of the dye. 


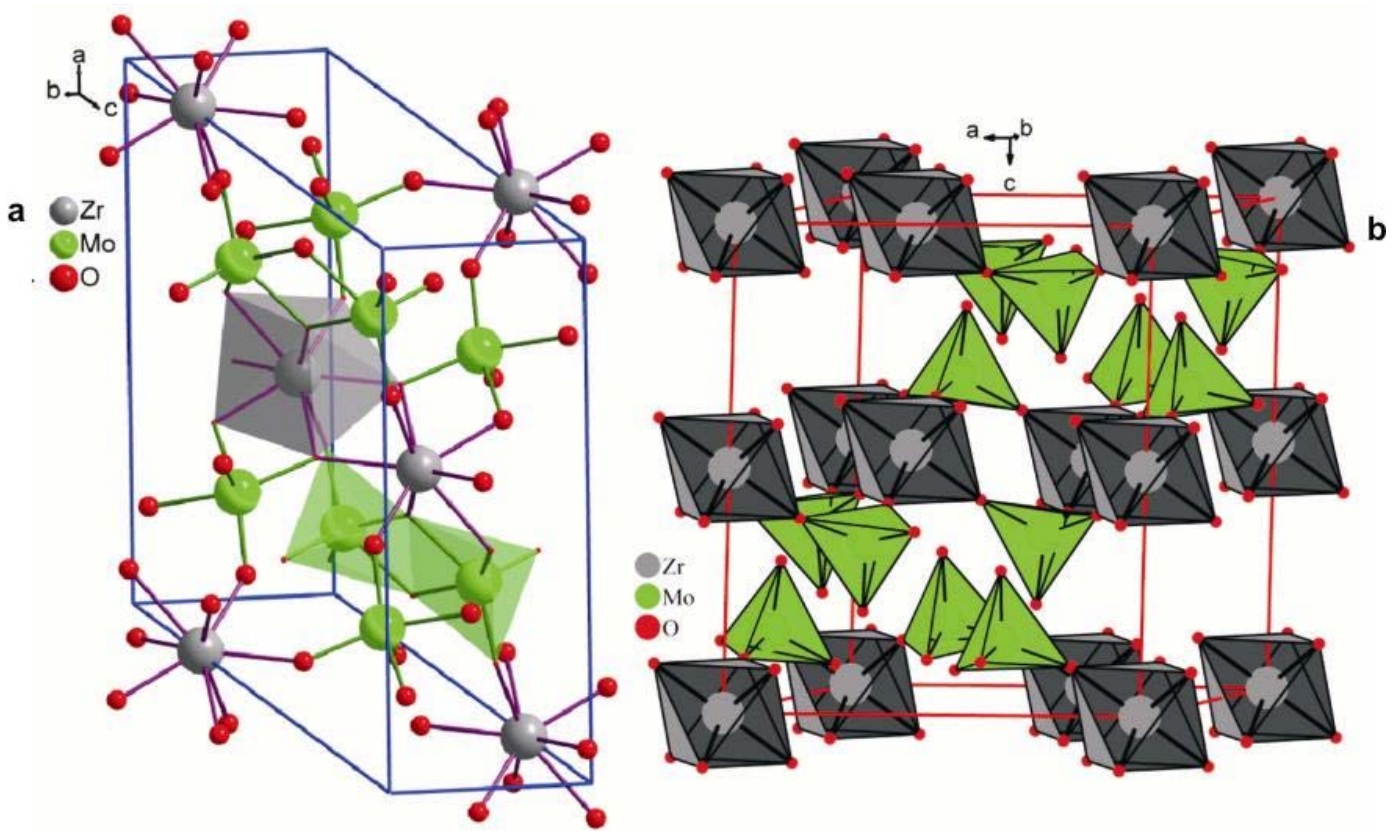

Figure 5. Polyhedral arrangement in the unit cell of a. monoclinic and b. trigonal $\mathrm{ZrMo}_{2} \mathrm{O}_{8}$.

\section{Results and discussion}

\subsection{Crystal structure}

The structure was solved from 902 unique reflections having $I \geq 2 \sigma$. The positions of $\mathrm{Zr}$ and Mo were determined using direct methods. The difference Fourier synthesis allowed locating the oxygen atoms. The structure has one zirconium, one molybdenum and four oxygen atoms. Zirconium occupies the special position (two fold symmetry, Wycoff $4 e$ ), whereas molybdenum and oxygen atoms occupy general positions $(8 f)$. Full occupancies were assigned to all the atoms. The final residual factors are $R_{1}=0.0187$ and $w R_{2}=0.0419$.

Zirconium is eight coordinated. $\mathrm{ZrO}_{8}$ polyhedra share edges forming a three dimensional network. Molybdenum is five coordinated and forms a tetragonal pyramidal structure. Two $\mathrm{MoO}_{5}$ polyhedra share edges with each other forming $\mathrm{Mo}_{2} \mathrm{O}_{8}$ moieties. It is noteworthy that the structure has $\mathrm{MoO}_{5}$ polyhedra unlike the other polymorphs where molybdenum forms $\mathrm{MoO}_{4}$ tetrahedra. Further, monoclinic polymorph depicts a unique $\mathrm{ZrO}_{8}$ polyhedral coordination whereas the other polymorphs of $\mathrm{ZrMo}_{2} \mathrm{O}_{8}$ have $\mathrm{ZrO}_{6}$ octahedra. These features are quite distinct from the other polymorphs of $\mathrm{ZrMo}_{2} \mathrm{O}_{8}$. The arrangement of the polyhedra along $b$ axis in the structure is presented in figure 4 . The comparison between the monoclinic and the trigonal forms in terms of the polyhedral arrangement in the crystal structure is shown in figure 5.

The Mo-O bond lengths vary from 1.674(2) to $2 \cdot 039$ (2) $\AA$. The $\mathrm{Zr}-\mathrm{O}$ bond lengths vary from $2 \cdot 118$ (2) to 2.312(2) $\AA$. Molybdenum is coordinated with all four kinds of oxygen atoms whereas zirconium is coordinated with $\mathrm{O}(2), \mathrm{O}(3)$ and $\mathrm{O}(1)$ oxygen atoms. Bond valence sums were calculated for molybdenum and zirconium atoms. For molybdenum atom, the value is $\mathbf{5 . 9 6 2}$ whereas for zirconium atom the value is $\mathbf{4 . 2 0 2}$.

\subsection{Photocatalysis}

Photocatalytic degradation of the dyes $\mathrm{MB}, \mathrm{OG}, \mathrm{RB}$, $\mathrm{RBBR}, \mathrm{CR}$ and $\mathrm{MG}$ was investigated. The lamp position in the photochemical reactor was adjusted such that no degradation occurred in the absence of UV light or the catalyst alone. Figure 6 shows the profiles of dye degradation in presence of monoclinic $\mathrm{ZrMo}_{2} \mathrm{O}_{8}$. It was observed that anionic dyes like OG and RBBR do not degrade in presence of this catalyst.

Among the cationic dyes that degraded, the following order was evident with the initial rates of degradation being $0.233,0.400,0.100$ and $0.183(\mathrm{ppm} / \mathrm{min})$ for $\mathrm{MB}$, $\mathrm{CR}, \mathrm{RB}$ and $\mathrm{MG}$, respectively. If a first order is assumed, the rate coefficients are $0.0031,0.0051,0.0111$ and $0.0131 \mathrm{~min}^{-1}$, respectively. The catalytic behaviour of the monoclinic polymorph is different from that of the trigonal polymorph. In our previous studies (Sahoo et al 2009), we have shown that the trigonal $\mathrm{ZrMo}_{2} \mathrm{O}_{8}$ could degrade all the dyes that do not contain the anthraquinonic group. However, this polymorph could not degrade any anionic dyes. Further studies are required to determine the reason of this specificity.

\section{Conclusions}

Monoclinic $\mathrm{ZrMo}_{2} \mathrm{O}_{8}$ was synthesized by solid state technique and the single crystals were grown hydrothermally. 

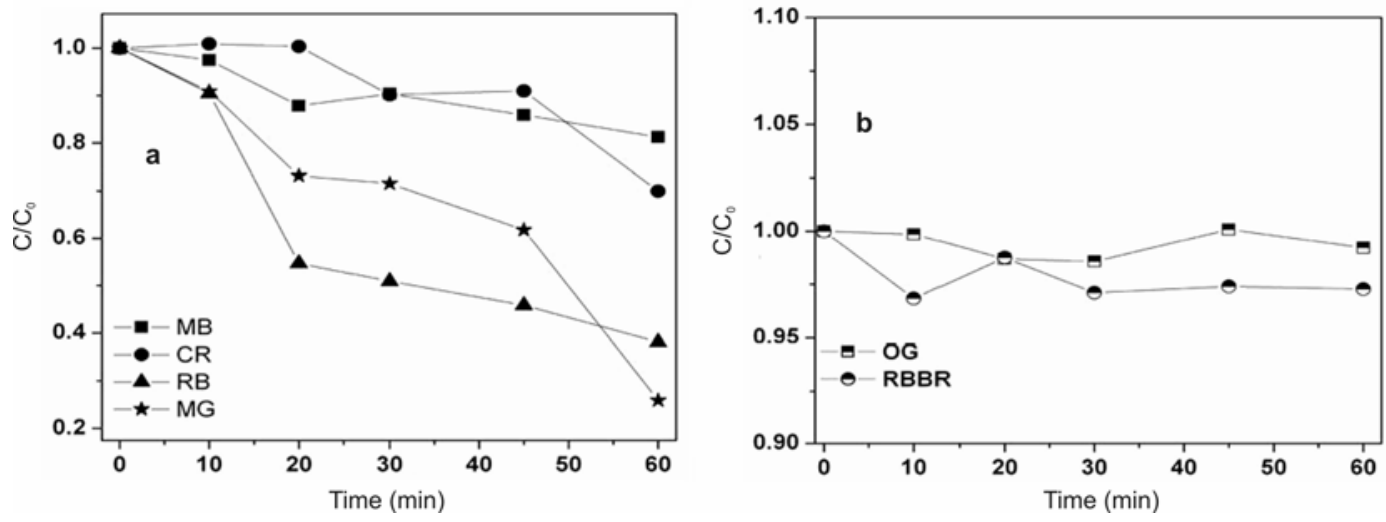

Figure 6. UV degradation of various a. cationic dyes and $\mathbf{b}$. anionic dyes in presence of monoclinic $\mathrm{ZrMo}_{2} \mathrm{O}_{8}$.

The photocatalytic activity of this polymorph has been studied for the first time. Since the reports available on the crystal structure of monoclinic modification of $\mathrm{ZrMo}_{2} \mathrm{O}_{8}$ were not rigorously accurate, we report the single crystal structure of the title compound. This reveals the difference in crystallographic features between the monoclinic and the trigonal modifications. The structure of monoclinic $\mathrm{ZrMo}_{2} \mathrm{O}_{8}$ consists of $\mathrm{ZrO}_{8}$ and $\mathrm{Mo}_{2} \mathrm{O}_{8}$ polyhedra unlike the other polymorphs of $\mathrm{ZrMo}_{2} \mathrm{O}_{8}$ including the trigonal form. The trigonal modification was found to be specific towards the degradation of nonanthraquinonic dyes whereas the monoclinic modification was found to be specific towards the degradation of cationic dyes. Hence, we emphasize the role of crystal structure in inducing the photocatalytic activity and specificity towards different class of dyes. The photocatalytic activity differs mainly due to the difference in bandgap originating from the crystallographic differences.

\section{Supporting information available}

CIF: the crystal data have been deposited at the Fachinformationszentrum Karlsruhe (FIZ) with the number CSD 420668 .

\section{Acknowledgements}

One of the authors (PPS) thanks the Indian Institute of Science for a senior research fellowship. We acknowledge funding from DRDO and DST, India. We thank DST-FIST, India for funding the single crystal X-ray CCD facility.

\section{References}

Allen S, Warmingham N R, Gover R K B and Evans J S O 2003 Chem. Mater. 153406

Allen S, Ward R J, Hampson M R, Gover R K B and Evans J S O 2004 Acta Crystallogr. B60 32

Andersen A M K and Carlson S 2001 Acta Crystallogr. B57 20
Auray M, Quarton M and Tarte P 1986 Acta Crystallogr. C42 257

Auray M, Quarton M and Tarte P 1989 Powder Diffraction 129

Blasse G and Dirksen G J 1987 J. Phys. Chem. Solids 48591

Brown I D and Shannon R D 1973 Acta Crystallogr. A29 266

Brown I D and Altermatt D 1985 Acta Crystallogr. B41 244

Carlson S and Andersen A M K 2000 Phys. Rev. B61 11209

Clearfield A and Blessing R H 1972 J. Inorg. Nucl. Chem. 34 2643

Dušek $M$, Petřiček $V$, Wunschel $M$, Dinnebier R $E$ and van Smaalen S 2001 J. Appl. Crystallogr. 34398

$\mathrm{Fu} \mathrm{H}$, Lin J, Zhang L and Zhu Y 2006 Appl. Catal. A306 58

Fujishima A and Honda K 1972 Nature 23837

Fujishima A, Rao T N and Tryk D A 2000 J. Photochem. Photobiol. C: Photochemistry Reviews 11 (and the references therein)

Grzechnik A and Crichton W A 2002 Solid State Sci. 41137

Karandikar A S, Mukherjee G D, Vijayakumar V, Godwal B K, Achary S N and Tyagi A K 2006 J. Appl. Phys. 100013517

Kim H G, Hwang D W and Lee J S 2004 J. Am. Chem. Soc. 126 8912

Klevtsova R F, Glinskaya L A, Zolotova E S and Klevtsov P V 1989 Dokl. Akad. Nauk SSSR 30591

Kudo A, Omori K and Kato H 1999 J. Am. Chem. Soc. 121 11459

Lind C, Wilkinson A P, Hu Z, Short S and Jorgensen J D 1998 Chem. Mater. 102335

Lind C, VanDerveer D G, Wilkinson A P, Chen J, Vaughan M T and Weidner D J 2001 Chem. Mater. 13487

Lind C, Wilkinson A P, Rawn C J and Payzant E A $2002 \mathrm{~J}$ Mater. Chem. 12990

Monroy-Guzmán F, Díaz-Archundia L V and Ramírez A C 2003 Appl. Radiat. Isot. 5927

Muthu D V S, Chen B, Wrobel J M, Andersen A M K, Carlson S and Kruger M B 2002 Phys. Rev. B65 064101

Sivalingam G, Nagaveni K, Hegde M S and Madras G 2003 Appl. Catal. B45 23

Sahoo P P, Sumithra S, Madras G and Guru Row T N 2009 J. Phys. Chem. C113 10661

Sheldrick G M 1997 SHELXL97 Program for crystal structure refinement (Germany: University of Gottingen)

Sudorgin N G, Nalbandyan V B and Shukaev I L 2008 Solid State Ionics 179503 